\title{
The Going Abroad of Chinese Online Literature to the Western World
}

\author{
Zhang Hanwen ${ }^{1, *}$ \\ ${ }^{1}$ College of Foreign Languages and Cultures, Sichuan University, Chengdu, China, 610000 \\ *Corresponding author. Email: zhanghanwen929@126.com
}

\begin{abstract}
These days, an increasing number of Chinese online novels are being translated and disseminated, gradually entering the Western world, such as Douluo Continent, which thanks to the commonality between Chinese and Western literature, whereas the process also contains certain areas that still need to be further improved. Based on the comparison between Western magic literature and Chinese online literature, as well as the content of original Chinese online literature and the content of translated texts, this research examines the current situation of the dissemination of Chinese online literature in the English-speaking world today, emphasizing the export of excellent Chinese online literature textual content, pointing out the shining points, similarities and learnability of the construction of Chinese and Western magic literature, enhancing the ethnicity embedded in it, and suggesting that the excellent traditional culture of the Chinese nation should be emphasized, so as to promote the overseas dissemination of Chinese culture.
\end{abstract}

Keywords: Chinese online novels, Western world, literature, translation

\section{INTRODUCTION}

In recent years, many online literature enterprises have responded to the national call to promote online literature abroad, using digital technology and Internet platforms to translate and publish a large number of online literature works that are easily accepted by foreign audiences, further spreading the strong voice of China and demonstrating the charm of Chinese cultural innovation to the world.

This research attempts to explore the feasibility of going abroad for Chinese online literature by using case studies and comparative analysis from the similarities and commonalities between Chinese online literature and Western culture. At the same time, it summarizes and reflects on the characteristics of Chinese online literature itself, as well as the technical advantages and disadvantages of translation styles and translators. In order to better export Chinese culture and promote the long-term development of Chinese online literature overseas.

\section{THE CONNECTION BETWEEN CHINESE ONLINE LITERATURE AND WESTERN MAGICAL LITERATURE}

\subsection{Character-centered construction model}

Online fantasy novels borrow a form of construct from traditional Chinese martial arts novels: character-centered martial arts constructs. Specifically, the characters are the soul of the work, and the behavior of the central character leads to the development of other characters, so that the reader can read the deeper meaning and moral hidden between the lines of the work from the characters' transformation experience[1]. A relevant instance is Xiao Yan, the main character of the famous online novel Fights Break Firmament, who lost all his skills at the age of 12 and experienced being withdrawn, bullied and ridiculed. However, when he was about to despair, he obtained a ring, which helped him to become a powerful person in the world again[2]. This kind of character growth from a nobody to a master tends to attract the reader's attention the most.

And in Western literature, there are countless texts that adopt a character-centered mode of construction. For example, the Harry Potter series, which is well known in the world of children's literature, revolves 
around the young wizard Harry Potter, the main character's six-year study life and adventures at Hogwarts. The main character from the beginning of ignorance and even some timid and cowardly, to later experience a series of exciting adventures to transform into a superb, righteous, and brave wizard, and ultimately defeated Voldemort. It can be seen that the character growth model is a common tactic in the construction of novels in the East and West.

The character-centered construction model is not the only similarity between Chinese and Western literature; the non-realistic world setting also bridges the gap between Chinese and Western readers.

\subsection{The Construction Model of the Fiction World}

Internet fantasy novels are often constructed by relying on a fiction world that is distinct from the real world. Internet literature is based on the primitive human thinking that all things are spiritual, and inherited from the ancient Chinese novels of gods, demons and monsters and the ancient Western epic heroic sagas.

Chinese online fantasy novels tend to divide the world into three levels: heaven, hell, and the human world. The classes of the three-fold world are not solidified and unchanging: shrewd and hardworking people can eventually attain immortality through their own efforts and through gradual cultivation. Ghosts follow the example of mortals, mortals follow the example of immortals, and this is the "three worlds" worldview that is cyclical and circulates with each other[3]. This "three worlds" worldview constitutes an Eastern narrative mode in online literature, which also provides the basis for the character growth mode of metaphysical fiction novels and their unique aesthetic experience of compensatory satisfaction. For example, in the novel Life After Life, Blooms Over Blooms, the hero and heroine go through three worlds, shuttling between the human world and the heaven world, and at the same time, they are entangled with people in the hell, which is a typical three-world view setting.

In Western fiction, there is also a tradition of constructing an otherworldly world distinct from the real world. However, due to the influence of religious beliefs, the concepts of heaven, earth, hell, and purgatory are common settings in Western fantasy novels. The Western fictions often set up an "other world" different from the real world we live in, which may be parallel to or intersect with the human world. The narrative model is also different from the Eastern style of personal cultivation experience, but rather heroes to protect or conquer the "other world"[3]. The famous Marvel series and The Lord of the Rings series both involve this form of world-building.
Thus, it seems that the world-building of online literature is crucial to both Chinese and Western novels, and there are commonalities between them, as the plots often cover the imagination of supernatural and unimaginable phenomena.

\subsection{Similar reading experience of Chinese and Western magical literature}

Additionally, there are similarities between the considerations made by Eastern and Western authors for readers' reading experience when writing, including providing sensory stimulation and compensatory satisfaction, which provides a certain basis for online novels to open up the overseas markets.

For example, when reading the Harry Potter series, although the contents of the books about magic, Nordic mythology and other elements may be confusing to Eastern readers, the stimulation of the senses brought by the overall plot story and the compensating satisfaction of the characters' reversal have laid a certain foundation for its popularity among readers from different countries and regions[4]. The descriptions of various spells, magic and exotic treasures in the book, as well as the scenes in which Harry earns honor for his college again and again at the end of the story, making the college leap from the last place to the first place, all give readers a great sense of satisfaction.

Similarly, in Chinese online novels, depending on the needs of the readers, the authors create different fantasy lives for the readers to enjoy, offering remedial satisfaction for the disappointment or dissatisfaction in the real world. For example, in the online novel Perfect World, Chen Dong describes a kind of technique named Heaven Mending, which can go back in time, change what has happened, and make up for past regrets. The existence of this setting reveals a complementary mentality towards people or things in the past, a mentality that emerges in relation to people's regrets about what they failed to accomplish in real life. Therefore, the world in metaphysical novels is also a strong medicine for people's empty and barren souls, because they can dream whatever they want in the fantasy world.

Online literature is like a clean slate that is different from the real world, a spiritual haven for readers. The exciting and intense fighting plots, delicate and provocative love and hate entanglements, the fast life of chivalry and righteousness, and even the immortality and reboot of life are realized in online fantasy novels, thus allowing readers to indulge in a sense of satisfaction that reality cannot bring. 


\section{ANALYSIS AND RESOLUTION OF THE CURRENT SITUATION OF CHINESE ONLINE LITERATURE TRANSLATION}

According to the research of 2017 Chinese Online Literature Overseas White Paper released by iResearch, since early 2015, the influence and radiation of Chinese online novels are increasing in the western world. Among them, the main translated genres of online novels are fantasy-themed and xianxia novels, and in addition to them, a series of romance novels are also loved by many foreign women. However, apart from the popularized novel genres mentioned above, including mystery, wuxia, immortal, and romance, very few works of elite online literature have been translated[6]. This imbalance in translation genres is largely influenced by the overseas readership and the limitations of the translators themselves.

\subsection{The impact of readership}

The largest user group for the overseas dissemination of Chinese online literature should be the young male student population in Europe and the United States who do not yet have income. Many readers are not highly educated themselves and know little about Chinese culture and language. Therefore, for the reading of Chinese elite online novels, their literary level is not up to it. In contrast, Chinese popularized online novels, mainly genre novels, have become very popular because of their simple and straightforward language and spiritual core similar to that of Western fantasy[8].

Take the novel Coiling Dragon for example, the founder of WuxiaWorld website, RWX, is of Chinese American descent, and their group of martial arts fans' spontaneous translations of the works of martial arts greats such as Jin Yong and Gu Long did not have enough impact in the English-speaking world at first, until RWX started translating the online novel Coiling Dragon, which gave Chinese translated novels a place in the world's popular culture. Coiling Dragon is one of the masterpieces of Western fantasy novels popularized in China. It is a story about a Western world set in typical "sword and magic", from the world setting to the naming of characters, it basically follows the conventions of European and American fantasy novels, which is not new to readers in the English-speaking world, and they can easily enter the novel. Coiling Dragon is a "cooking" of "raw materials" from Europe and the United States in a way that has become increasingly mature in China's online fiction[8]. Some of the philosophies it preaches in the simplest way may not seem worthwhile to some experts, but it succeeds in opening the door to Chinese online novels to a significant portion of readers who know nothing about traditional culture.

\subsection{The limitations of translators}

The translation of Chinese online novels began with fan translation. These fans are themselves fans of a particular writer or genre of online literature, who devote their passion to it because of their hobbies and spend their spare time participating in translations on their own initiative. They are the earliest promoters of Chinese online literature overseas and are typical of the fan culture, so the choice of the genre of Chinese online novels to translate is often linked to the translators' own interests and preferences[7]. WuxiaWorld, an English-language translation website established in December 2014, was initially developed by the creation of translation groups driven by the personal preferences of overseas fans of online literature.

On the other hand, although there is a wide variety of genres and topics in Chinese online literature, and there are also countless outstanding elite online literature works, it often takes years to translate an online work because of its long length and often millions of words. In addition, the quality of online literature varies, which is a challenge for the translator's comprehensive ability. At the same time, there is a lack of active and competent translators. The translation of elite online literature not only takes huge time and effort, but also requires extremely demanding requirements on the translators' literary level, Chinese and Western cultural level and language ability. CKtalon, a translator of Webnovel, has used the immortal cultivation system in Chinese mystery novels to classify the translators into grades. He believes that most of the translators are still in "Foundation Phase", i.e. translating word by word and sentence by sentence according to the original text. This kind of translation can only let the readers understand roughly what people are doing and what they are doing. Translators in "Virtuoso Phase" will make the story more vivid. They will let the reader understand the plot while increasing the overall readability and fluency. Elite online literature requires a translation of the "immortality" level. However, due to the difficulty and high requirements, such high-level translators are currently rare, and naturally, translations of elite online literature are also very rare.

\subsection{The coping strategies}

Some commentators have proposed refined translations of online literature. Excellent online novels deserve to be matched with the quality of responsible translations toward international classics, so as to achieve the double-wing effect of overseas dissemination. With the help of professional translators, and after marketization, professional translation teams and full-time contract translators, the quality and efficiency of translation will naturally be much better 
than that of spontaneous amateurs. If there is official support to organize a team of Chinese and foreign translators and set up a special translation platform for elite online texts, and if Chinese and Western experts cooperate with each other, we may be able to get twice the result with half the effort[6].

As for how to attract overseas readers' interest in Chinese elite online novels, and thus stimulate the development of fine and accurate translations with demand, it is a good strategy to focus on creating cultural derivative products of online literature[6]. Typical examples of this are the lively full industry chain and multi-time development model represented by Tang Jia San Shao's Douluo Continent and Nan Pai San Shu's Tomb Notes, as well as the success of quality film and television adaptations such as A Nai's realistic-themed Da Jiang Da He. Culture is presented in a variety of forms, in addition to the form of text, can also be presented in the form of film and television, graphics, animation, games and so on. If the storytelling, graphics and cultural load of elite online literature can be integrated and presented in an interesting and entertaining form, it should be more easily accepted by the overseas public, which in turn will lead to their interest in the original work and their demand to read the translated work.

\section{CONCLUSION}

The dissemination and development of Chinese online literature in the English-speaking world have admittedly encountered many difficulties, but an optimistic and positive mindset should be maintained to help promote its overseas development.

Promoting Chinese online literature abroad has, first of all, spread Chinese culture and expanded its influence on the younger generation overseas. Chinese online novels themselves are rich in Chinese culture. Take translated mainstream mystery novels as an example, the stories are often set in Chinese myths and legends and historical texts, which are very different from the cultural background of the Western world and have a unique appeal to overseas readers. In the process of reading, readers also become more interested in Chinese culture and are constantly influenced by the subtle influence of Chinese culture. Second, it breaks the cultural export trap and innovates the content of cultural communication. The Chinese government attaches great importance to Chinese culture going abroad, but the traditional Chinese cultural export often focuses on presenting excellent traditional culture, and some of the content is obscure and difficult to understand, so even foreign readers who are interested in Chinese culture sometimes have difficulty understanding it and can only be deterred. Chinese online novels, however, have broken this dilemma, attracting a large number of foreign readers with their easy-to-understand content.
Studying the spread of Chinese online literature in the Western world is conducive to better promoting Chinese culture to the world.

Nevertheless, this research lacks specific case studies on the difficulties encountered in the translation process of Chinese online novels, which needs further analysis and studies.

\section{ACKNOWLEDGMENTS}

I would like to extend my deep gratitude to all those who have offered me a lot of help and support in the process of my thesis writing.

First and foremost, my sincere thanks go to Professor Wang Lingzhen, who has been instrumental in helping me learn to apply a comparative perspective on Eastern and Western literature.

Also, I owe many thanks to my teaching assistant, who answered my ignorant questions and provided me with numerous useful information and tips on the structure, methods and techniques of academic research. Additionally, I have benefited from many teachers who helped me to revise my paper and made suggestions to improve the details and clarify my ideas.

Last but not least, I am deeply indebted to my family and friends, who have helped me and shared with me my worries, frustrations, and happiness.

\section{REFERENCES}

[1]Liu Yueyong. Research on online metaphysical novels $[\mathrm{J}]$. Internet $\quad$ Literature Review,2019(06):16-23.

[2]Meng Sui. The relevance of online fantasy novels to readers' daily lives: A case study of Tian Can Tu Dou's works[J]. Educational Media Research,2019(05):90-94.

[3]Ge Hongbing, Liu Sai. The Three Realms Model and the Other Continents Model: A Comparison of Two Basic Narrative Models and Their "Worldviews" in Genre Fiction[J]. Contemporary Writers Review,2019(04):4-10+2.

[4]Zhang Si. A study of untranslatability and translation compensation theory: Harry Potter as an example[J]. Farmers' Counselor,2019(05):175.

[5]Fan Lingfeng. The translator's sense of style in novel translation[J]. Overseas English, 2014(07):108-109+117.

[6]Xin Feng. Research on the current situation, problems and countermeasures of overseas dissemination of Chinese online literature[J]. Satellite TV and Broadband Multimedia,2019(10):108-110. 
[7]Tang Weiqi, Zhang Zhiwu. Research on the overseas dissemination of Chinese online novels in the context of cultural "going abroad"[J]. Journal of Hubei Open Vocational College,2019,32(23):190-191+194.

[8]Xue, Jiefu. Research on the extra-territorial dissemination of Chinese online novels based on audience analysis[D]. Xi'an University of Technology,2018. 